\title{
Analisa pengaruh media pendingin dan arus listrik pada proses pengelasan titik (spot welding) stainlees steel terhadap nilai kekuatan tarik
}

\section{Tri Cahyo Wahyudi ${ }^{*}$, Sulis Dri Handono², Hendi Ahmad Sanjaya ${ }^{3}$, Abdul Basir Sulaiman Azis ${ }^{4}$}

\author{
1,2Jurusan Teknik Mesin, Fakultas Teknik, Universitas Muhammadiyah Metro \\ Jl. Ki Hajar Dewantara 15 A Kota Metro, Lampung, Indonesia \\ ${ }^{3,4}$ Prodi Teknik Mesin, Fakultas Teknik, Universitas Muhammadiyah Metro \\ Jl. Ki Hajar Dewantara 15 A Kota Metro, Lampung, Indonesia \\ ${ }^{*}$ Corresponding author: tricahyowahyudi3@gmail.com
}

\begin{abstract}
Welding is one of the metal joining techniques by melting some of the parent metal and filler metal under pressure and with or without additional metal so as to produce a continuous welded joint. The cooling medium and electric current in this welding process greatly affect the welding results. Lap joint is one type of welding connection that exists in spot welding, namely the type of pile connection. This study uses AISI 316 Stainless Steel plate. The purpose of this study was to determine the tensile strength and the type of coolant with which current is the most optimal for tensile loading. The welding time is equalized, which is 2 seconds and the parameters used are ordinary water, salt water, mineral water and variations in currents of 660 Ampere, 880 Ampere and 1100 Ampere. The tests carried out were tensile tests using the Ultimate Testing Machine. In the test results, it was found that the most optimum type of lap joint connection to be given tensile loading from the yield strength value was ordinary water cooling at 1100 Ampere currents of $159.17 \mathrm{~kg} / \mathrm{mm}^{2}$, tensile strength with mineral water cooling at 1100 Ampere currents of $195.92 \mathrm{~kg} / \mathrm{mm}^{2}$, and the elongation value with mineral water cooling at a current of 1100 Ampere is $11.19 \%$.
\end{abstract}

Keywords: Spot welding, lap joint, stainlees steel, tensile strength.

\begin{abstract}
Abstrak
Pengelasan adalah salah satu teknik penyambungan logam dengan cara mencairkan sebagian logam induk dan logam pengisi dengan tekanan dan dengan atau tanpa logam penambah sehingga menghasilkan sambungan las yang kontiyu. Media pendingin dan arus listrik pada proses pengelasan ini sangat mempengaruhi hasil pengelasan. Lap joint adalah salah satu jenis sambungan las yang ada pada las titik yaitu jenis sambunga tumpuk. Penelitian ini menggunakan plat baja Stainlees Steel AISI 316. Tujuan dari penelitian ini adalah untuk mengetahui kekuatan tarik dan jenis pendingin dengan arus berapa yang paling optimal untuk diberikan pembebanan tarik. Untuk waktu pengelasan disamakan yaitu 2 detik dan untuk parameter yang digunakan adalah media pendingin air biasa, air garam, air mineral dan variasi arus 660 Ampere, 880 Ampere dan 1100 Ampere. Pengujian yang dilakukan adalah pengujian tarik menggunakan alat Ultimate Testing Machine. Pada hasil pengujian didapat bahwa jenis sambungan lap joint yang paling optimum untuk diberikan pembebanan tarik dari nilai yield strength yaitu pendingin air biasa pada arus 1100 Ampere sebesar $159,17 \mathrm{~kg} / \mathrm{mm}^{2}$, tensile strength dengan pendingin air mineral pada Arus 1100 Ampere sebesar 195,92 kg/mm², dan nilai elongation dengan pendingin air mineral pada arus 1100 Ampere sebesar $11.19 \%$.
\end{abstract}

Kata kunci: Spot welding, lap joint, stainlees steel, kekuatan tarik. 


\section{Pendahuluan}

Teknologi, maka industri pada saat ini mengalami kemajuan yang sangat pesat. Karena pesatnya kemajuan teknologi, maka banyak sekali proses produksi yang menggunakan proses pengelasan, karena pengelasan mempunyai kelebihan seperti hasil sambungan lebih kuat, mudah untuk pemakaian, murah dan efisien [1]. Las dalam bidang konstruksi sangat luas penggunaannya meliputi konstruksi jembatan, perkapalan, industri karoseri dan sebagainya. Disamping untuk konstruksi, las juga dapat untuk mengelas cacat logam pada hasil pengecoran logam dan mempertebal logam yang aus [2].

Dari berbagai macam jenis pengelasan di Indonesia proses pengelasan yang populer digunakan dalam industri otomotif terutama mobil untuk pengerjaan body atau kerangka mobil adalah menggunakan las titik [3].

Las titik (Spot Welding) adalah salah satu metode pengelasan yang prinsip kerjanya menggunakan arus listrik untuk menyambung pelat logam. Proses pengelasannya yaitu dengan menjepit dimana satu atau lebih pelat menggunakan elektroda. Siklus pengelasannya yaitu dengan memberikan tekanan pada pelat kemudian mengalirkan arus listrik dalam jumlah yang besar. Akibat besarnya arus listrik yang diberikan, maka bagian pelat yang ditekan dan diberi arus akan memanas dan meleleh, tekanan elektroda yang diberikan pada pelat akan dilepas sesaat setelah arus dialirkan agar pelat yang dilas dapat menempel dengan sempurna [4].

Kualitas dan kekuatan lasan titik sangat penting terhadap perancangan umur dan keamanan dari suatu kendaraan. Prosesnya yang mudah, ekonomis, dan cepat sehingga cocok untuk produksi masal, suplai panas yang diberikan cukup akurat dan reguler, sifat mekanik hasil las kompetitif dengan logam induk dan tidak memerlukan kawat las [5]. Proses pengerjaan las ini lebih rapi hasilnya dan tidak mengandung terak las. Media pendingin dan besarnya arus listrik pada pengelasan ini sangat mempengaruhi karakteristik hasil pengelasan karena pengontrolan ini mempengaruhi kualitas hasil las yang optimal, seperti kekuatan geser, kekerasan dan kekuatan terhadap pengaruh dari luar [6].

Penggunaan stainlees steel dalam las titik dikarenakan bahan tersebut tahan terhadap korosi, mudah dibentuk dan dilas, tahan terhadap temperatur panas tinggi maupun rendah, dan desain produk yang sangat berkualitas. Untuk mengetahui sifat mekanik dari sambungan baja dapat dilakukan melalui uji tarik pada material/logam tersebut. Kekuatan tarik pada sambungan las sangat dipengaruhi oleh sifat logam induk, daerah HAZ (heat affacted zone), sifat logam las, dan geometri serta distribusi tegangan dalam sambungan [7].

Berdasarkan pemaparan diatas, peneliti melakukan analisa beberapa parameter pengelasan yaitu pengaruh media pendingin dan arus listrik pada Stainlees Steel terhadap nilai kekuatan tarik. Dengan demikian diharapkan penelitian ini akan diketahui kondisi optimal dari sambungan material/logam tersebut yang paling baik.

\section{Tinjauan Pustaka}

\section{Pengelasan}

Pengelasan merupakan teknik penyambungan logam dengan cara mencairkan sebagian logam induk dan logam pengisi dengan atau tanpa tekanan dan dengan atau tanpa logam penambah dan menghasilkan sambungan yang kontiyu.

\section{Sambungan las}

Sambungan antara dua logam dengan cara pemanasan, dengan atau tanpa logam pengisi. Sambungan terjadi pada kondisi logam dalam keadaan plastis atau leleh. Sambungan las banyak digunakan pada konstruksi serta pada permesinan. Ada lima jenis sambungan dasar pada pengelasan, antara lain, yaitu Jenis sambungan las butt joint, lap joint, t-joint, edge joint, corner joint. 


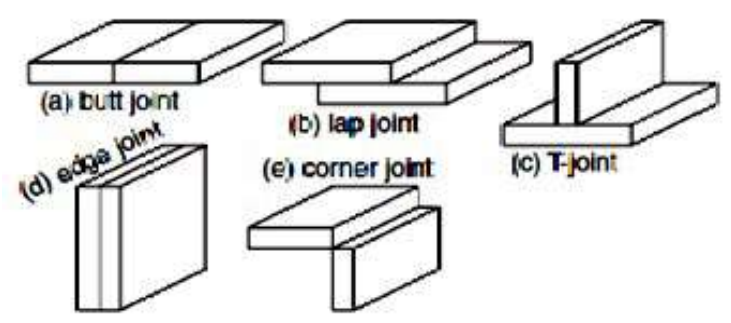

Gambar 1. sambungan pada pengelasan

\section{Las titik (Spot Welding)}

Pada las titik, logam yang akan disambungkan di jepit dengan elektroda dari paduan tembaga dan kemudian dialiri arus listrik yang besar dalam waktu yang sangat singkat. Karena aliran listrik antara kedua elektroda tersebut harus melalui (logam) plat yang dijepit, maka pada tempat jepitan timbul panas yang menyebabkan logam ditempat tersebut mencair dan tersambung. Pada tempat kontak antara elektroda dan logam yang tidak di las juga terjadi panas karena tahanan listrik, tetapi tidak sampai mencairkan logam karena ujung elektroda didinginkan [8].
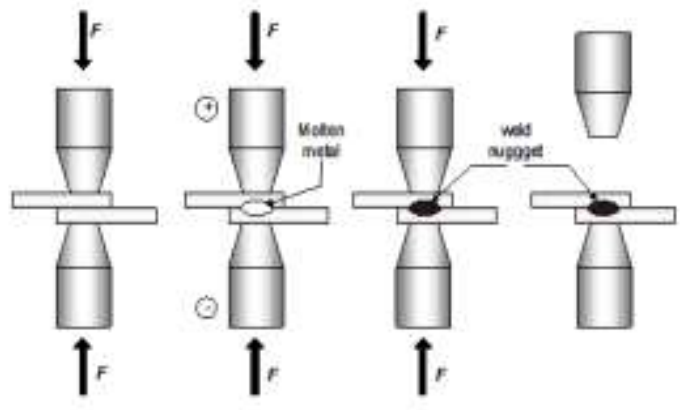

Gambar 1. Proses Pengelasan Titik

\section{Pendingin dan arus listrik}

Pemilihan media pendingin dan penggunaan arus listrik sangat mempengaruhi hasil penyambungan logam optimal atau tidaknya, menggunakan media pendingin yang berbeda separti air biasa, air garam, dan air mineral. Fungsi media pendingin pada pengelasan titik yaitu untuk mendinginkan elektroda pada saat proses pengelasan dengan fase sirkulasi melalui lengan tekan sehingga hasil pengelasan bisa optimal.

\section{Metode Penelitian}

\section{Diagram Alir Penelitian}

Secara skematik, prosedur penelitian ini dapat digambarkan dalam bentuk diagram alir seperti berikut:

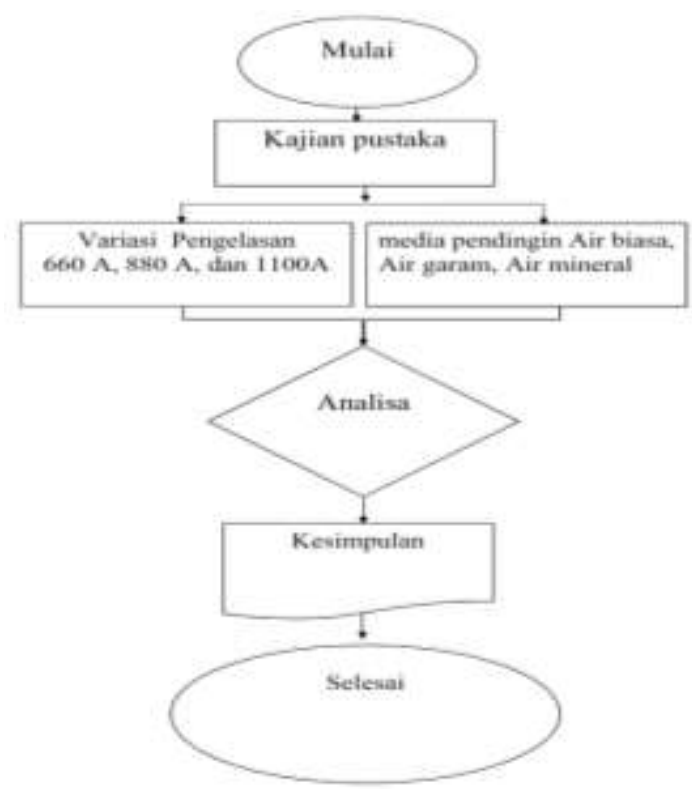

Gambar 3. Diagram alir penelitian
Alat Yang digunakan
1. Mesin las titik
2. Alat uji tarik
3. Penggores plat
4. Mesin pemotong plat
5. Sikat dan amplas
6. Gerindra
7. Mistar

\section{Bahan yang digunakan}

Pada penelitian ini bahan yang digunakan adalah baja tahan karat AISI 316 dengan komposisi kimia yang ditunjuka pada tabel 1 .

Tabel. Komposisi kimia plat baja stainless steel AISI 316.

\begin{tabular}{ccccccc}
\hline $\begin{array}{c}\text { Mate } \\
\text { rial }\end{array}$ & $\mathrm{C}$ & $\mathrm{Si}$ & $\mathrm{Mn}$ & $\mathrm{P}$ & $\mathrm{S}$ & $\mathrm{Cr}$ \\
\hline $\begin{array}{c}\text { Stain } \\
\text { lees }\end{array}$ & 0.1 & 0.4 & 10. & 0.0 & 0.0 & 14. \\
steel & 49 & 64 & 52 & 661 & 062 & 56 \\
\hline
\end{tabular}

\section{Prosedur pengelasan}

Plat baja stainlees steel dengan ketebalan $0,8 \mathrm{~mm}$ dilas dengan 
memvariasikan media pendingin air, air garam dan air mineral serta arus pengelasan 660 Ampere, 880 Ampere, dan 1100 Ampere, dengan waktu pengelasan dilakukan selama 2 detik.

\section{Uji kekuatan Tarik}

Pembuatan spesimen uji kekuatan tarik didasarkan pada standar JIS Z 3139, bentuk spesimen uji kekuatan tarik berukuran panjang $150 \mathrm{~mm}$, lebar $30 \mathrm{~mm}$, serta jarak antara titik las dan ujung tumpuk an plat $15 \mathrm{~mm}$.

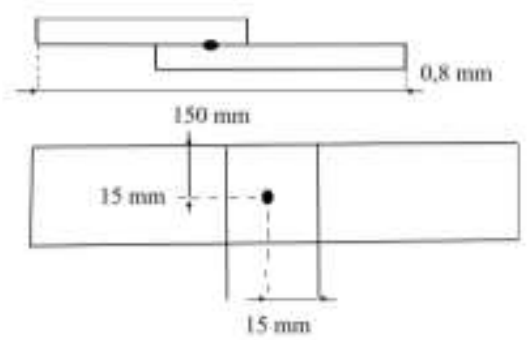

Gambar 4. Bentuk spesimen uji kekuatan tarik standar JIS Z 3139 [9].

Setelah dilakukan uji kekuatan tarik, didapatkan nilai yang berbeda -beda menurut variasi media pendingin dan arus listrik. Seperti yang ditunjukkan pada nilai tensile strength pada pendingin air biasa.

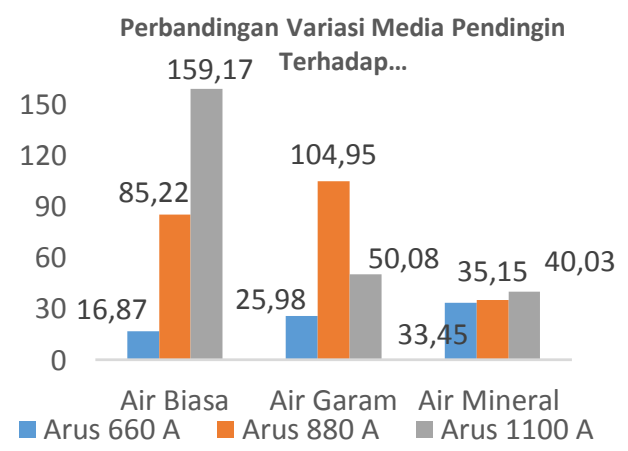

Gambar 5. Nilai perbandingan variasi pendingin terhadap yield strength

Pada gambar 5 di atas dapat dilihat nilai Yield Strength tertinggi yaitu pada media pendingin air biasa sebesar 159,17 $\mathrm{kg} / \mathrm{mm}^{2}$ pada arus listrik 1100 Ampere,kemudian mengalami penurunan pada pendingin air garam pada arus 880 Ampere sebesar $104.95 \mathrm{~kg} / \mathrm{mm}^{2}$, mengalami penurunan kembali pada arus 110 Ampere dengan pendingin air mineral sebesar 40.03 $\mathrm{kg} / \mathrm{mm}^{2}$. Bisa kita lihat dari perbandingan variasi media pendingin yang berbeda pada nilai maksimum yield strength, hal ini disebabkan karena arus listrik yang tinggi maka timbul fasa bainit dan martensit yang kekerasannya tinggi, maka kekuatan tarik sambungan las berkurang, bahwa semakin tinggi arus listrik pada pengelasan ini, semakin besar daerah HAZ, akibatnya menurunya kandungan perlit diiringi terjadi peningkatan ferrite pada HAZ, karena pada daerah las, panas yang diterima logam lebih besar.

Hal ini terbukti pada perubahan bentuk yang terjadi pada material tersebut lebih tinggi yaitu pada kekuatan luluhnya, walaupun beban yang bekerja ditiadakan [10].

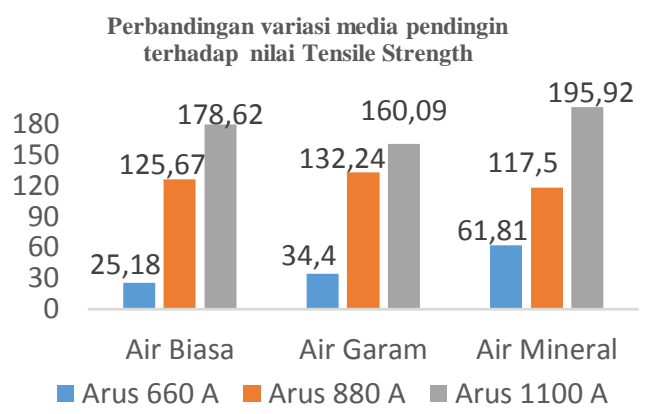

Gambar 6. Nilai perbandingan variasi pendingin terhadap tensile strength

Seperti pada gambar 6 di atas nilai tensile strength dari perbandingan media pendingin dapat dilihat nilai tensile strength tertinggi yaitu pada media pendingin air mineral pada arus 1100 Ampere sebesar $195,92 \mathrm{~kg} / \mathrm{mm}^{2}$, kemudian mengalami pada pendingin air biasa pada arus 660 Ampere sebesar 178,62 $\mathrm{kg} / \mathrm{mm}^{2}$, serta pada pendingin air garam pada arus 880 Ampere sebesar $160 \mathrm{~kg} / \mathrm{mm}^{2}$. Semakin besar kuat arus dan waktu pengelasan pada proses spot welding yang digunakan maka nilai kekuatan tarik pada material juga akan semakin tinggi [11]. 


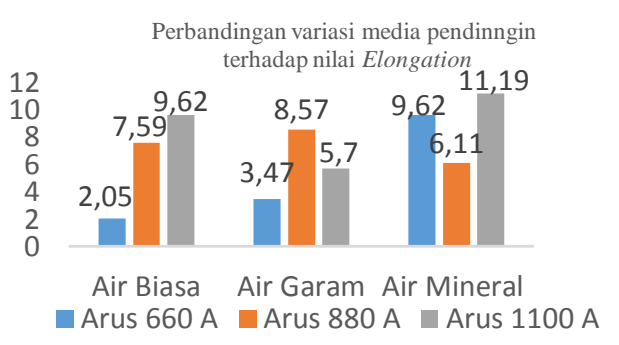

Gambar 7 Nilai Perbandingan variasi pendingin terhadap Elongation

Seperti pada tabel gambar 7 di atas nilai Elongation dari perbandingan variasi media pendingin dapat dilihat nilai elongation tertinggi yaitu pada media pendingin air mineral dengan arus 1100 Ampere sebesar $11.19 \%$, kemudian pada pendingin air biasa pada arus 660 Ampere sebesar $9.62 \%$, mengalami serta pada pendingin air garam dengan arus 880 Ampere sebesar $8,57 \%$. Bisa dilihat pada gambar 13, dari variasi arus pada pendingin air mineral nilai tertinggi elongation masing-masing berbeda. Hal ini terbukti semakin getas suatu material, maka keuletannya akan semakin rendah, sehingga material mudah dipatahkan dengan energi yang relatif lebih rendah. Variasi media pendingin dan arus listrik sangat berpengaruh terhadap kekuatan lasan, tegangan luluh dan perubahan sifat mekanisnya, besar kecilnya arus listrik dan media pendingin,akan mempengaruhi kecepatan rambatan yang terjadi, baik saat atau setelah pengelasan, Sehingga akan berpengaruh pada pembentukan fasa akhir yang terbentuk dan akan menentukan kekuatan sambungan las.

Semakin tinggi arus pengelasan yang digunakan maka nilai kekuatan tarik pada material juga akan semakin tinggi [12], terlihat pada grafik di atas nilai rata-rata kekuatan tarik maksimal yaitu pada media pendingin air mineral pada arus listrik 1100 Ampere sebesar 195,92 kg/mm². Hal ini membuktikan bahwa media pendingin pada proses pengelasan titik sangat berpengaruh pada hasil pengelasan. Untuk jenis sambungan tumpuk (lap joint) pada pengelasan titik yang paling optimal ini terjadi pada variasi media pendingin air mineral dengan arus listrik 1100 Ampere, ini dikarenakan diameter nugget (manik las) yang terbentuk lebih besar, dan pengelasan pun dilakukan secara tumpuk pada dua permukaan yang mengakibatkan panas tidak hanya terjadi pada satu sisi material, maka hasil sambungan las titik pada plat baja stainlees steel ini akan semakin kuat sehingga gaya tarik yang dibutuhkan untuk diameter manik las tersebut semakin besar. Pemilihan parameter las titik yang tepat, akan berpengaruh terhadap kekuatan lasan dan perubahan sifat mekanisnya. Besarkecilnya arus listrik dan lama waktu operasi las akan mempengaruhi kecepatan rambatan yang terjadi, baik saat atau setelah pengelasan. Sehingga akan berpengaruh pada pembentukan fasa akhir yang terbentuk dan akan menentukan kekuatan sambungan las [13].

\section{Kesimpulan}

Dari hasil penelitian dapat disimpulkan bahwa jenis sambungan lap joint yang paling optimum untuk diberikan pembebanan tarik dari nilai yield strength yaitu pendingin air biasa pada arus 1100 Ampere sebesar $159,17 \mathrm{~kg} / \mathrm{mm}^{2}$, tensile strength dengan pendingin air mineral pada Arus 1100 Ampere sebesar 195,92 kg/mm², dan nilai elongation dengan pendingin Air mineral pada arus 1100 Ampere sebesar $11.19 \%$

\section{Referensi}

[1] Purwaningrum, Yustiasih, Fatchan M. 2013“Pengaruh Arus Listrik Terhadap Karakteristik FisikMekanik Sambungan Las Titik Logam Dissimilar Al-Steel' 'ROTASI - Vol. 15, No. 1, Januari 2013: 16-22.

[2] Haryono Wiryosumarto, Teshi Okumura. 1991. "Teknik pengelasan logam”. Cetakan kedelapan. Jakarta: PT Pradnya Paramita.

[3] Pouranvari, M \& Marashi, S.P.H. 2011. Dissimilar Spot.Weld of AISI 304 / AISI 1008: Metallurgical and 
Mechanical Characterization. Steel Research Journal, 82 (12): 13551360.

[4] Amstead, B.H., (1995), Teknologi mekanik, Edisi ke7 jilid 1, PT. Erlangga, Jakarta.

[5] Anis, M., Irsyadi, A., \& Ferdian, D. 2009. Studi lapisan intermetalik $\mathrm{Cu}_{3} \mathrm{Sn}$ pada ujung Elektroda dalam pengelasan titik baja galvanis. Jurnal teknologi, 13 (2): 91-95.

[6] Arifin, 1997. Las listrik dan otogen. Jakarta: Ghalia Indonesia.

[7] Wiryosumarto, H. 1996. "Teknologi Pengelasan Logam", PT. Pradnya Paramita journal of Manufacturing Science and Engineering, August 2001 Vol. 123.

[8] Hendri, 2012. "Analisa kekuatan tarik hasil spot welding baja karbon rendah" Jurnal teknik mesin Vol.1, No.2, Institut Teknik Padang.

[9] JIZ, hand book, Ferrous Material and, Tokyo Japanase Standart Acociation 1984.

[10] Nurhidayat Achmad, Triyono, 2012. "Pengaruh Waktu Dan Arus Listrik Pengelasan Rsw Terhadap Sifat Fisik Dan Mekanik Pada Sambungan Logam Tak Sejenis Antara Baja Tahan Karat SS 316 Dan Baja Karbon ST37".

[11] Agustriyana, L, Yudi S.I \& Sugiarto. 2011. "Pengaruh Kuat Arus dan Waktu Pengelasan Pada Proses Las Titik (Spot Welding) Terhadap Kekuatan Tarik dan Mikrostruktur Hasil Las Dari Baja Fasa Ganda (Ferrite Martensite)', Jurnal Rekayasa Mesin, 2 (3): 175-181.

[12] Purwaningrum, Y., \& Fatchan, M. 2013. "Pengaruh arus listrik terhadap karakteristik fisik - mekanik sambungan las titik logam dissimilar Al-steel ',. Jurnal teknik mesin, 15 (1): 16-22.

[13] Wiryosumarto, H., 2004, Teknologi Pengelasan Logam, PT. Pradya Paramita, Jakarta. 